\title{
Entre Lacan y Benjamin: la segunda muerte como asunto de la redención. Pervivencia [Nachleben] y experiencia histórica
}

Q Ludmila Fuks

Universidad de Buenos Aires, Argentina

Recibido el 13/12/2019/Aceptado el 3/3/2020

\begin{abstract}
Resumen
En la tesis VI de Sobre el concepto de historia (1940) de Walter Benjamin nos encontramos con la sentencia de peligro en que se encuentran los muertos, que podemos pensar como amenaza de una muerte simbólica de la tradición oprimida. Si hay una segunda muerte es porque hay una vida después de la muerte natural, es decir una pervivencia [Nachleben] del pasado en el presente. Esta pervivencia, en el contexto de las tesis de 1940, es posible hilarla con las nociones de experiencia [Erfahrung] histórica y la transmisión de la misma. Frente al peligro de desaparición absoluta de aquello que ha quedado trunco, el autor alemán expone la necesariedad de salvarlo, es decir redimirlo. En este sentido, la redención operaría como una resistencia frente a la segunda muerte, noción que elabora Lacan en 1960. El ensayo que aquí llevaremos a cabo será pensar los posibles cruces entre las nociones benjaminianas de pervivencia, experiencia histórica y redención, y la noción lacaniana de segunda muerte, para así pensar entre ambos autores la dualidad de la muerte en tanto natural y simbólica (o espectral), lo fallado de la muerte natural y lo absoluto e irreversible de la segunda muerte.
\end{abstract}

\section{Between Lacan and Benjamin: second death as a matter of redemp- tion. Survival [Nachleben] and historical experience}

\begin{abstract}
In thesis VI of Walter Benjamin's On the Concept of History (1940), we find the sentence of danger in which the dead are, which we can think of as a threat of a second death, or symbolic death of the oppressed tradition. Now, if there is a second death it is because there is a life after natural death, that is a survival [Nachleben] of the past in the present. This survival, in the context of the theses of 1940 , is possible to weave it with the notions of historical experience [Erfahrung] and the transmission thereof. Faced with the danger of the absolute disappearance of what has been truncated, the German author exposes the need to save it, that is, to carry out a redemption, a remembrance. In this sense, redemption would operate as a resistance of the
\end{abstract}

\section{Palabras clave}

Experiencia histórica Lacan Nachleben Segunda muerte Walter Benjamin
Keywords

Historical experience Lacan Nachleben Second death Walter Benjamin 
1. Las tesis Sobre el concepto de historia de Benjamin se citan de acuerdo a la citación estándar de las Obras completas [Gesammelte Schriften]: los números romanos corresponden al número de tomo y las cifras arábigas al número de página.

2. Como señala Vargas "alejado del modelo evolucionista darwinista, el concepto de Nachleben se inscribía dentro de las 'Ciencias del Espíritu' en el marco de un modelo no antropomórfico de la historia de la cultura, que no se orientaba según el ritmo propio de las edades humanas (infancia, adolescencia, adultez, vejez), ni se proyectaba en estadios o etapas de desarrollo, pero que, sin embargo, consideraba que los productos culturales estaban dotados de una vida y una vitalidad propias. Pensadores tan disímiles entre sí, tales como Friedrich Nietzsche, Georg Simmel, Sigmund Freud, Wilhelm Dilthey, Aby Warburg y Walter Benjamin, colocaron en el centro de sus intereses la cuestión de la vida propia del pasado y de las manifestaciones culturales y sociales entendidas como dotadas de una energía y vida propias" (2017: 38). Para un estudio pormenorizado sobre el concepto de Nachleben ver los artículos de Vargas $(2014 ; 2017)$ aquí referenciados. second death, a notion that Lacan elaborates in 1960 . Here we will essay thinking this possibles intersections between the benjaminians notions of survival, historic experience and redemption, and the lacanian notion of second death, for being able to think the duality of natural and simbolic death. the failed of natural death and the absolut and irreversible character of second death.

\section{I.}

La reliquia procede del cadáver, rememoración

de la experiencia ya difunta (Benjamin, 2008: I, II 290)

\begin{abstract}
- ¿Acaso lo más viejo no se entera siempre de la llegada de lo nuevo?
-Quizás. Habla como si creyera en los espíritus.

-Creo en las obras, y hay muchas obras en Marte. Hay calles y casas, e imagino que también habrá libros, y grandes canales, y relojes (...) en todas partes veo cosas usadas. (...) si usted me pregunta si creo en el espíritu de las cosas usadas, le diré que sí. Ahí están todas esas cosas que sirvieron para algo. Nunca podremos utilizarlas sin sentirnos incómodos. Y esas montañas, por ejemplo, tienen nombres... Nunca nos serán familiares; las bautizaremos de nuevo, pero sus verdaderos nombres son los antiguos. (Bradbury, 1998: 87)
\end{abstract}

La tesis VI de Sobre el concepto de historia [1940] de Walter Benjamin culmina de la siguiente manera " $[\mathrm{e}] 1$ don de encender la chispa de la esperanza solo es inherente al historiógrafo que esté convencido de que ni los muertos estarán seguros ante el enemigo si es que este vence. Y ese enemigo no ha cesado de vencer." (2008: I, II 308) ${ }^{1}$. Es a partir de esta sentencia de peligro en que se encuentran los muertos que se puede pensar que la amenaza es la de una segunda muerte, muerte simbólica de la tradición oprimida de la cual el historiógrafo tiene que estar alerta (Reyes Mate, 2006; Naishtat en Abadi 2014; Zizek, 2003). Ahora bien, si hay una segunda muerte es porque hay una vida después de la muerte natural, es decir una pervivencia [Nachleben] del pasado en el presente. La noción de Nachleben forma parte del pensamiento alemán de fines de siglo XIX y principios del siglo $\mathrm{XX}$, principalmente referido a elementos culturales en el ámbito de la filosofía de la cultura y del arte, pero también se vuelve central en las reflexiones sobre la transmisión y la memoria (Vargas, 2017). ${ }^{2}$ Ahora bien, en el contexto de las tesis benjaminianas de 1940, la pervivencia es posible hilarla con las nociones de experiencia [Erfahrung] histórica y la transmisión de la misma. Frente al peligro de desaparición absoluta de aquello que ha quedado trunco, el autor alemán expone la necesariedad de salvarlo, es decir de realizar una redención, una rememoración. En este sentido, la redención opera como segunda chance, o segunda instancia, de aquellos que ya han tenido una muerte natural, y que por tanto perviven, se encuentran en su "sobre-vida", que se encuentra al borde de desaparecer. La redención, en estos términos, se reconfigura como una forma de resistencia, entonces, frente al posible aniquilamiento que enterraría definitivamente aquellos significantes, aquellas memorias. Veinte años después de la escritura de estas tesis, Lacan articula, principalmente en los seminarios 7, 8 y 9, la noción de segunda muerte. La misma opera como simbolización de la primera muerte. Es decir, en tanto muerte absoluta se diferencia de la muerte natural, y por tanto actúa como aniquilación de la potencia significante. Sin embargo, no necesariamente la segunda muerte ocurre después de la primera, como se ve en el texto lacaniano sobre Antígona, que se encuentra en realidad en el entre-dos-muertes. Es a partir de esta noción de segunda muerte que pretendemos iluminar aquello que no aparece nominado en el texto benjaminiano, pero que ocupa el lugar frente al cual operaría la redención. 
Así como lo señala Oliveira (2016) los trabajos sobre las posibles aproximaciones entre Lacan y Walter Benjamin son escasos (Berrebi 2013; Stewart 2010; Comay 2003; Zizek 2003). En efecto, aunque ya esté establecida la influencia de la teoría psicoanalítica de Freud en la teoría benjaminiana, Lacan en ningún momento lo cita o nombra. Lo que resulta más que interesante es que ambos autores piensan y abordan problemáticas por momentos similares, aunque sus respuestas sean singularmente diferentes. Así como ambos colocan la cuestión del lenguaje y del nombre en la base de su teoría, ${ }^{3}$ también se dedican a leer la tragedia antigua, a relacionarla con Hamlet y a pensar el silencio socrático. ${ }^{4} \mathrm{El}$ ensayo que aquí llevaremos a cabo será pensar los posibles cruces entre ambos autores a partir de las nociones benjaminianas de pervivencia, experiencia histórica y redención, y la noción lacaniana de segunda muerte. De esta manera, lo que esta articulación permitiría alumbrar es este aspecto que no se encuentra teorizado de manera acabada en la obra benjaminiana, es decir, la muerte simbólica como aquello a lo que pretende hacerle frente la redención. Asimismo, asentar algunos trazos de lectura entre dos autores que operan de manera crítica abre un campo de lecturas cruzadas que potencia rasgos de sus pensamientos y los actualiza, como el estatuto del ser en el lenguaje en torno de la cuestión simbólica. Ahora bien, no pretendemos realizar un desarrollo minucioso de la exposición lacaniana sobre la segunda muerte, ni una teorización acabada de la muerte simbólica en Benjamin, sino más bien pensar entre ambos autores la dualidad de la muerte y la vida en tanto natural y simbólica (o espectral), lo fallado de la muerte natural -las remanencias y posibilidades de redención que permite dejar-y lo absoluto e irreversible de la segunda muerte. Es decir, un pensar situado topológicamente entre sus pensamientos para rodear ese más allá de la muerte natural que es la muerte en la vida o la muerte definitoria del pasado. ${ }^{5}$

\section{La segunda muerte lacaniana}

Es principalmente en los seminarios 7, 8 y 9 donde Lacan aborda la noción de segunda muerte a partir de sus análisis sobre la tragedia y especialmente su lectura de Antigona. A partir de esta lectura se distinguen dos muertes: una muerte natural, que es parte del ciclo biológico y por tanto está atada al cuerpo natural, y por encima y más allá de él, es como si hubiera un cuerpo exceptuado de lo orgánico, al que se le puede dar una muerte absoluta, segunda muerte que es simbolización de la primera. Zizek expone que se diferencia así la primera muerte "en la que pierdo una de mis vidas y la muerte definitiva en la que pierdo el juego" (2003: 181). La segunda muerte es el "ajuste de cuentas", el más allá del límite, el infierno y el castigo. Aparece como sufrimiento infringido, como tormento, es donde Lacan sitúa la lectura sadeana del tormento eterno. ${ }^{6}$ Traspasar el límite de la segunda muerte es el Ektòs, el afuera Ektòs átas, y en tanto superación de un límite, ya no hay salvación, es "Ektòs elpídos más allá de toda esperanza" (Lacan, 1988: 157). ${ }^{7}$ Traspasar el límite de la segunda muerte implica, a su vez, sacrificar aquello en lo que uno reconoce su ser mismo. La segunda muerte sadeana se expresa como borramiento de aquello que sostiene la huella desp ués de la muerte natural, como la tumba y la memoria, figurándose así como "la no huella (pas de traces) (...) aniquilamiento de la potencia significante" (Lacan, 1961-1962: 83). Así, Lacan señala a la segunda muerte como la forma de morir eternamente, que en tanto absoluta elimina todo resto posible, y se diferencia de la muerte natural, en donde lo inanimado deja una huella, aunque ésta sea bajo la forma de muerte, del recuerdo y la lápida. ${ }^{8}$

En esta línea, la segunda muerte se configura tanto como límite como un lugar, pero que no ocurre necesariamente después de la muerte natural. La muerte simbólica en vida es también posible. Antígona encerrada viva en la tumba está en el lugar de esta muerte que profana, usurpa, rasga la vida, le hace perder su potencia relacional. Vive,
3. Sobre la filosofía del lenguaje benjaminiana ver Collinwood-Selby, Elizabeth (1997); y sobre el cruce entre ésta teoría y la lacaniana ver Stewart (2010).

4. Lacan aborda estos temas en los seminarios que tratamos aquí, y Benjamin en su Ursprung des deutschen Trauerspiels (1928).

5. No lo abordaremos aquí, pero el nudo Borromeo es construido por Lacan como una topología, justamente para poder pensar cómo los diferentes registros (Simbólico, Real, Imaginario) se imbrican y yuxtaponen. En este período de su obra la topología es conceptualizada principalmente en la Clase 12 del Seminario IX: La identificación de Lacan (1961-1962), pero las conceptualizaciones específicas sobre lo borromeo (nudos y trenzas) están más bien en el "último" Lacan (1974-1981).
6. Además de la lectura lacaniana que aquí apuntamos, la muerte sadeana es punto de atención de múltiples pensadores como Foucault ([1970-1971] 2015. Conferencias sobre Sade. En La gran extranjera. Para pensar la literatura. Buenos Aires: Siglo XXI), Barthes ([1971] 2002. Sade, Fourier, Loyola. En Euvres complètes. T. III. París: Seuil), Bataille (1971. La literatura y el mal. Madrid: Taurus), Blanchot ([1949] 1990. Lautréamont y Sade. México DF: Fondo de Cultura Económica), Adorno y Horkheimer ([1944] 2007. Dialéctica de la ilustración, Madrid: Akal).

7. La numeración de páginas de los seminarios de Lacan corresponden a la versión digital indicada en la bibliografía. 8. Esta diferencia entre la muerte y lo inanimado refiere a la cuestión del goce y pulsión de muerte, que retoma asimismo de Freud. La muerte es el límite del goce de la vida, pero asimismo es un límite que devela lo perverso del juego con su posibilidad. Sobre este punto, ver Kant con Sade (1962) y Seminario 18: De un discurso que no fuera del semblante (1971). 
9. "La dimensión del lenguaje es anterior e independiente del sujeto. Pero engendra el sujeto en el viviente. El sujeto nace en el hombre por la intervención del lenguaje sobre el organismo, no hay sujeto antes del lenguaje" (Negro, 2009: 6).

10. De aquí la importancia del duelo, como es posteriormente trabajado por Butler (2006) en Vida precaria. El poder del duelo y la violencia. Buenos Aires: Paidós. El luto es tematizado también por Benjamin en su Ursprung des... (op.cit). pero se encuentra atrapada por la segunda muerte, en la zona del entre-dos-muertes. "A partir de ese momento, franqueada lo que encarna en ella la entrada en lo que es, si pudiera decirse, el simétrico de esta zona más allí, entre la muerte y la vida, entre la muerte física y el borramiento del ser, ella - sin estar aún muerta - está ya tachada del número de los vivos" (Lacan 1988: 161). La segunda muerte se articula, entonces, como borramiento del ser, en términos de una zona de suspensión. Suspensión donde no es llorada por nadie, donde no hay lápida con nombre, sólo lamentación de la vida, donde evoca incluso que no tendrá niños, por lo que podríamos decir se corta la cadena de transmisión de experiencia. Es una vida que no vale la pena ser vivida porque la segunda muerte, como campo límite, es una salida de los límites humanos en tanto que sobre lo que opera es lo simbólico. Es decir, al final de cuentas sobre lo que hace sujeto al ser, sobre lo que diferencia al humano de lo cósico o de lo animal. ${ }^{9}$ La segunda muerte se articula, entonces, como límite, como Até, es decir "lo que designa el límite que la vida humana no podría franquear por mucho tiempo" (Lacan, 1988: 152), en tanto que más allá de él sólo queda el Ektòsátas.

A partir de la lectura de Antígona se nos devela la importancia de la sepultura del hombre en términos de ser situado por un nombre, en tanto que ser nombrado es ser reconocido. Es decir de dar la segunda vida a través del significante, que permite eternizar al sujeto, inscribir su legado de una forma singularmente humana -el lenguaje- como el nombre, que se preserva por el acto mismo del funeral, de lo que ese ser fue. Tener una sepultura inscribe al sujeto en la cadena significante, es pasar a la memoria de la posteridad. ${ }^{10} \mathrm{Y}$ esto es un valor único de la característica humana, valor que es del lenguaje, fuera del lenguaje no puede ser concebido. Así, la falta de sepultura actúa como una muerte simbólica, que a su vez se encuentra, en tanto límite, en "el mismo corte que instaura en la vida del hombre la presencia misma del lenguaje" (Lacan, 1988: 161). En este sentido, esta muerte corresponde al ser que habla, en tanto que "es por la cadena significante que se constituye como posibilidad ese lugar y que es también por ella, que podemos representarnos ese más allá del retorno de lo inanimado" (Giner Ponce, 2002: 6). Así, lo que de algún modo permite la persistencia de aquello que retorna del pasado -o se mantiene en el presente de manera espectral- es justamente su inserción en el registro simbólico, la cadena significante. La muerte absoluta es, al final, la destrucción del universo simbólico, expone Zizek, en términos de que es la "posibilidad de 'supresión' total de la tradición histórica abierta por el proceso de simbolización/historización” (2003: 182).

\section{Pervivencia [Nachleben] y experiencia [Erfahrung] histórica en Walter Benjamin}

En la filología alemana de 1920 se encuentran numerosos desarrollos del concepto de pervivencia [Nachleben], que como expone Vargas (2014), implica la vida del muerto en el recuerdo, es decir la vida después de la muerte natural. Todo aquello que vivió y que actuó continúa haciéndolo incluso después de su muerte natural, es decir que el pasado no se encuentra acabado sino que pervive de forma reconfigurada en el presente. Esta noción se encuentra también presente en Benjamin, en donde los productos culturales contienen una vitalidad propia, en tanto que ciertas expresiones, elementos u objetos retornan o perviven bajo una "circulación encubierta en forma de detalles en imágenes" (Vargas, 2014: 320). En esta línea, "la 'pervivencia' expresa más bien la permanencia de algo con vida, a pesar de que muchas otras cosas hayan cambiado o desaparecido. Lo que pervive tiene una sobre-vida, una vida después de la vida" (Vargas, 2014: 324), como sucede, por ejemplo, con las obras de arte -lo cual tiene también sus consecuencias respecto del ámbito de la historia y la historiografía. En este sentido es que los muertos no mueren del todo, sino que más bien asumen otra forma de vida. Podríamos decir que así como las obras de arte se 
transforman de manera discontinua, también la experiencia [Erfahrung] histórica está cargada por las generaciones, se transmite en la memoria y pervive en ella, como lo señala en el Convoluto $\mathrm{N}$ del Libro de los Pasajes "la 'comprensión' histórica se ha de tomar fundamentalmente como vida póstuma de lo comprendido, y por eso lo que se alcanzó a conocer en el análisis de la 'vida póstuma de las obras', de la 'fama', ha de considerarse por encima de todo como la base de la historia en general" (Benjamin, 2016: 463). La vida póstuma [Nachleben] de las obras de arte es necesario tenerla presente como posibilidad, latencia, en la comprensión que hacemos en el presente de lo histórico en general.

Es, principalmente, a partir de los textos de la década del '30, El narrador. Consideraciones sobre la obra de Nikola Lesskow y Experiencia y pobreza, donde podemos puntualizar esta noción de experiencia entendida como urdimbre o ámbito de transmisión. En ellos, Benjamin expone el diagnóstico de que en la sociedad de posguerra el arte de narrar, el arte de contar historias, se está perdiendo y, ligado a esto, que hay un empobrecimiento de la experiencia. Que este arte se esté perdiendo implica un empobrecimiento de la facultad del intercambio de las experiencias a nivel de la lengua. El hecho de que "la gente volvía muda del campo de batalla" (Benjamin, 1986a: 190) expone la situación de que la capacidad de contar historias deja de existir. De esta manera, a partir de El narrador... se desprende que las experiencias se entienden de manera colectiva a partir de su carácter comunicable, y de la mano con esto, la idea de transmisión aparece en el corazón de la propuesta benjaminiana. Como plantea Amengual "la pérdida de la experiencia (...) señala una ruptura de la tradición, tanto en el sentido activo (acto y proceso de transmitir) como en sentido pasivo (el contenido de sabiduría que se transmite)" (2008: 57). Lo que se transmite en la narración es "el consejo entretejido en la tela de la vida vivida, es sabiduría" (Benjamin, 1986a: 192), es aquello capaz de ser articulado en palabras, es decir que aquello que se encuentra en el ámbito de la tradición se contiene en el ámbito del lenguaje, o más bien, que experiencia y lengua son inseparables (Collingwood-Selby, 1997). La concepción de experiencia se encuentra así ampliada, en tanto que incluye en sí dimensiones históricas, religiosas, singulares, y "articula la experiencia del presente con el pasado, la vida personal con la del género humano, lo antiguo con lo nuevo" (Sargiotto, 2014: 113). En este sentido, se contrapone a la idea de vivencia [Erlebnis], e incluso al ser esta considerada transitoria, niega la experiencia porque no precipita o sedimenta en ella, y no contiene así caracteres de transmisión. La experiencia, así entendida, no es la del ser individual, sino que, en tanto urdimbre, articula diferentes generaciones del lenguaje, y por tanto a lo largo del tiempo. Amengual sostiene que la propuesta es "ampliar el concepto de experiencia a través de la memoria (la memoria pura, involuntaria, la rememoración) (...) tanto en su dimensión individual como colectiva" (2008: 55). Así, esta extensa trama podríamos también llamarla memoria, la cual se remonta en el tiempo posibilitando la vía de la transmisión, y conservando lo narrado.

Ahora bien, el aspecto sobre la experiencia que se enfatiza en las tesis de 1940 es más bien aquel en la esfera de la historia, en "eso que tiene lugar, también como disciplina, entre lo muerto y renaciente a la vez" (Vargas, 2014: 329). De esta manera, es en la experiencia histórica en donde tienen su segunda vida los muertos, es en el nivel simbólico de los significantes con los que construimos su memoria. Lo que acecha, como veremos, es el peligro de la segunda muerte y de aquí la exigencia de salvataje sobre los que no tienen voz, es decir sobre aquellos elementos pervivientes que podrían perderse. En este sentido, así como "[1]as imágenes del pasado sobreviven espectralmente en el sujeto histórico que debe darles vida (y despertarlas)" (Tacceta, 2012: 8), este también debe evitar que sean aniquiladas definitivamente. Se desprende así "la responsabilidad que comparten el historiador y el artista, pues deben recoger esos residuos en los márgenes del discurso histórico triunfante para reinscribirlos en un nuevo orden a fin de rehacer la historia" (Tacceta, 2012: 7). 
Volvemos entonces al final de la tesis VI, donde encontramos esta advertencia de que ni los muertos están a salvo del enemigo. Las tesis se sitúan a su vez en la crítica a la ideología del progreso que subyace tanto a las historiografías historicistas como al fascismo. Las mismas presentan la historia con narraciones en las que priman sólo las grandes figuras y las tradiciones dominantes, en tanto que operan sobre una continuidad temporal y una esencialización de lo histórico, es así como lo falluto, lo pequeño, lo sin nombre, es ocultado en este tipo de historiografía. Por esto la advertencia benjaminiana sobre lo históricamente desechado y su memoria, que el enemigo pretende conquistar para su propia tradición. Lo que está en peligro es esa imagen fugaz de un pasado fragmentario, es la experiencia histórica de un pasado que es único en su presentación, y en tanto que instante, se encuentra constantemente al borde de su disipación. Sobre este se libra en el presente una batalla hermenéutica, es la tradición de los oprimidos la que se encuentra en peligro de ser perdida, en tanto que es en el presente en donde se construye también el sentido sobre una tradición que en tanto trunca tiene una voz débil. Pero asimismo "si quiere evitar la segunda muerte del asesinado, el crimen hermenéutico, (...) necesita que el pasado no "esté ahí" inerte, sino que se haga presente" (Reyes Mate, 2006: 120). Es decir, nos encontramos con un pensamiento presente en distintas partes de la obra benjaminiana que es el de un movimiento doble respecto a lo pasado. Aquel pasado que pervive no está inerte o absolutamente inanimado, pero sobre él también hay que ejercer una rememoración, una redención, es decir que hay que realizar un encuentro entre pasado y presente. El pasado se encuentra latente en el presente, a la manera de la posibilidad, de la espectralidad de las cosas, y la redención opera a la manera de un salvataje mediante, al final de cuentas, una asignación de sentido retroactiva. La noción de redención recorre casi toda la obra de Benjamin (Abadi, 2014) con diferentes modulaciones y en particular en la obra tardía en relación con la rememoración [Eingedenken] sobre un pasado que se encuentra abierto. Así, en la tesis III expone

[e]l cronista que refiere los acontecimientos sin distinguir entre grandes y pequeños tiene con ello en cuenta la verdad de que nada que haya acontecido se ha de dar para la historia por perdido. Por supuesto que solo a la humanidad redimida le incumbe enteramente su pasado. Lo cual quiere decir que solo para esa humanidad redimida se ha hecho convocable su pasado en todos y cada uno de sus momentos (Benjamin, 2008: I, II 306).

11. En nuestra lectura, la tarea de la redención no opera de manera absoluta, sino que más bien conserva el carácter singular y fragmentario de aquello que redime, conservando así el aspecto fallado, no borra la huella, la cicatriz, como se ve en la figura cabalística del tikkun y en el montaje como contra-narración y método epistemo-crítico redentivo.

Nos encontramos entonces con un presente posible, lo que hubiera pasado si aquel pasado no hubiera sido malogrado. Su posibilidad continua latente en el hoy, en la experiencia histórica, el deseo frustrado de los muertos se puede convertir en felicidad si es redimido de su frustración, incorporado en la experiencia del presente. ${ }^{11}$ Pensar la verdad de la experiencia histórica para Benjamin, como lo señala Oyarzún "exige prendarse de esto sido, mantener abierta, desde el saber de su caducidad, su apertura póstuma a la significación, cuya cifra - como se arguye en los escritos sobre el lenguaje a que aludí más atrás- es el nombre" (2009: 14). Si bien no lo vamos a profundizar, habría que tener en cuenta -al menos como trasfondo para el siguiente apartado- estos textos que menciona el filósofo chileno, Sobre el lenguaje en generaly el lenguaje de los hombres (1916), La tarea del traductor (1923), en donde Benjamin esboza su teoría del lenguaje. El mismo es un ámbito que excede a lo meramente humano, pero lo nominativo tiene un lugar central incluso después de la caída y de la pérdida de la lengua pura, en tanto que el ser espiritual del hombre se condensa en el nombre propio de forma originaria. ${ }^{12}$ Además, como vimos, es en la lengua en donde se teje la experiencia, en tanto que es constitutiva del ser, este es en ella. De esta manera, en el contexto de los escritos de 1940 lo que se pretende condensar en la experiencia histórica sería justamente la débil pervivencia de la tradición enmudecida, cuyos significantes y nombres propios, se encuentran en peligro. 
El presente se encuentra entonces en una relación dialéctica con el pasado, en tanto que hay una presencia, una pervivencia de los ausentes en el presente (como aparece en la tesis $I I$, nos roza el mismo soplo de aire que a nuestros antecesores). Por tanto, el presente y el pasado no son puntos fijos en la historia, sino que se encuentran enlazados por una exigencia redentiva latente en la experiencia histórica, mantienen entre ellos una complicidad, en la que el presente se tiene que reconocer. La pervivencia de lo muerto y el peligro de pérdida de esta sobre-vida lo encontramos en el ensayo continuo que realiza Benjamin en sus textos con la exposición de los desechos, las colecciones de citas, como una "operación de rescate sobre los objetos del mundo" (Abadi, 2014: 220). El pasado mantiene carácter vital en tanto que "aún puede hablar" (Benjamin, 2016: 465), la época histórica se devela "tan cercana y tan lejana", como expone en el Libro de los Pasajes, en tanto que es en la experiencia histórica donde tienen su segunda vida los muertos. Asimismo, en tanto que es único en su presentación y excluido de la tradición dominante, se presenta la amenaza de muerte absoluta. El pasado que interesa aquí recuperar no es el de la continuidad, sino más bien el que fue interrumpido y que está al borde de su disipación. Si esa experiencia no se inserta en el registro de la cadena significante, si no se le da el nombre adecuado, no quedarán huellas (pas de traces diría Lacan, Spur diría Benjamin) y se perderá eternamente. Se articula así que recuperar las discontinuidades de la historia implicaría una redención en términos de resistencia de la segunda muerte sobre aquello interrumpido.

\section{Lacan esquina Benjamin. La redención y la muerte simbólica}

A la manera de una pregunta y un ensayo, a partir y en torno de lo ya expuesto sobre la segunda muerte, es posible realizar algunos cruces a partir de cómo entre Lacan y Benjamin podemos pensar la experiencia histórica, manteniendo abierta la distancia que hay entre el pensamiento benjaminiano, dedicado a formas de lo histórico principalmente en términos colectivos, y el pensamiento psicoanalítico lacaniano situado en torno a la historia del sujeto singular.

Como adelantamos, la figura de la redención, en Walter Benjamin, se expone como la meta justa para con nuestras generaciones anteriores, en tanto que pretende salvar el sentido a punto de ser olvidado, enterrado. "La tarea de rememorar obtiene su significado último de la justicia exigida por los acontecimientos pretéritos" (Abadi, 2014: 228), de esto se desprende que la nominación adecuada de lo sido es un asunto de justicia, incluso cuando la nominación originaria y la lengua pura estén ya perdidas, dejando así la experiencia de la palabra sin una mediación de significación. ${ }^{13}$ Así, "esa apropiación del pasado que el presente 'redime' retroactivamente -cuando el pasado está, en consecuencia, incluido en el presente- es el del significante" (Zizek, 2003: 188), redimir es en esta línea realizar en lo Simbólico. Es el movimiento retroactivo por el cual se le confiere sentido a aquello que no se encontraba en el entramado simbólico por haber sido excluido de la tradición dominante. Como expusimos, el presente cuenta con posibilidades latentes de lo que pudo ser de otra manera, de aquello que ya tuvo su muerte natural pero continúa vivo débilmente en el recuerdo y que en tanto trunco pervive a la manera de una latencia. Estas experiencias, históricamente oprimidas, contienen su posibilidad de justicia en el presente a partir de la redención, porque esta refiere al salvataje de lo trunco, tiene por objetivo resistir el aniquilamiento total de la potencia significante. Esta segunda muerte es absoluta en tanto y en cuanto el lenguaje se sitúa no como instrumento del sujeto, sino como aquello que da lugar al mismo, tanto en Benjamin como en Lacan ${ }^{14}$. Asimismo, en el más allá de la muerte simbólica, como expusimos, Lacan sitúa la imagen infernal, y de manera similar para Benjamin el tiempo que no condensa lo experiencial responde al tiempo infernal, de eterna repetición, "en el cual transcurre la existencia de aquello a los cuales no les es dado llegar a concluir nada de lo que han comenzado"
13. Como expone Collinwood-Selby "El nacimiento de la palabra humana es al mismo tiempo el nacimiento del 'paraíso' y de la lengua paradisíaca, ya que ambos sólo pueden entenderse como 'aquello que se ha perdido', y el hombre sólo es hombre, y la lengua humana sólo es lengua humana debido a esa pérdida" (1997: 112 ss.). Esto refiere a los textos de Benjamin en donde desarrolla su filosofía del lenguaje, como Über Sprache überhaupt und über die Sprache des Menschen (1916) [Sobre el lenguaje en general y el lenguaje de los hombres], y Die Aufgabe des Übersetzers (1923) [La tarea del traductor]. 14. Siguiendo a Collinwood-Selby, para Benjamin el sujeto es en el lenguaje dado que "(...) [l]a diferencia, la constante remisión a algo otro que sí mismo que se da a la vez en el ser y en la lengua, en tanto el ser y la lengua se revelan como escisión, como fractura, como deseo, no puede ser dicha, ni puesta de manifiesto por un lenguaje entendido como instrumento de comunicación, como modo de decir lo que se quiere decir" (1997: 116). Y sobre Lacan Zelis nos indica "La relación entre el hombre y el orden simbólico no conjuga con la idea del lenguaje como instrumento del hombre. Lacan es contundente: "Si el hombre llega a pensar el orden simbólico, es que primeramente está apresado en él su ser". "Es el orden simbólico el que es, para el sujeto, constituyente. “ (Lacan, 1985: 6). Y por si quedara alguna duda, sentenciará: "primero está el símbolo, que es la estructura misma del pensamiento." (1954/1981: 328)" (2016: 815). Ahora bien, es importante señalar que para Benjamin el lenguaje no es algo característico sólo de lo humano, las cosas también tienen su lenguaje. 
15. "La historia no es el pasado. La historia es el pasado historizado en el presente, historizado en el presente porque ha sido vivido en el pasado" (Lacan, 1981: 27).

16. "En la medida en que las diversas épocas del pasado quedan afectadas en un grado completamente distinto por el presente del historiador (a menudo el pasado más reciente le pasa completamente desapercibido al presente, este 'no le hace justicia')" (Benjamin, 2016: 473)

17. Aún más, en el ensayo Sobre algunos temas en Baudelaire [1939] (1986b), que aquí retomamos, Benjamin trabaja la noción de experiencia [Erfahrung] como memoria involuntaria proustiana -formada por residuos mnemónicos- a partir de Allende el principio del placer de Freud (1921).

18. "En efecto, la experiencia es un hecho de tradición, tanto en la vida privada como en la colectiva. La experiencia no consiste principalmente en acontecimientos fijados con exactitud en el recuerdo, sino más bien en datos acumulados, a menudo de forma inconsciente, que afluyen a la memoria" (Benjamin, 1986b: 90).
(Benjamin, 1986b: 111). La redención se articularía entonces como un hacerle frente a la segunda muerte que la tradición dominante pretende realizar, al borramiento de las huellas que dejó la muerte natural, de los trazos que se insertan en la memoria. Es así una apropiación de las pervivencias del pasado desde una mirada que no comulga con la vencedora -con la historiografía historicista y con el fascismo-. Lo que esto implica es una apoyatura no en una temporalidad continua sino en el pasado abierto, de lo que "podría haber sido", de los deseos latentes, por lo que la dimensión futura está ya contenida y por tanto nos permitiría redimir retroactivamente lo fallido y salvarlo del eterno tormento.

Como señala Lacan en el seminario I, la historia no es el pasado per se, sino más bien éste temporalizado en el presente. ${ }^{15}$ Este pasado no está obliterado, sino que más bien se constituye-se actualiza- en el hoy con la rememoración. Benjamin transcribe en el Libro de los Pasajes una carta que le envía Adorno, y en su respuesta le discute el pensamiento de un pasado que tenga carácter cerrado: "la historia no es sólo una ciencia sino no menos una forma de rememoración. Lo que la ciencia ha «establecido», puede modificarlo la rememoración. La rememoración puede hacer de lo inconcluso (la dicha) algo concluso, y de lo concluso (el dolor) algo inconcluso" (2016: 474). En los primeros seminarios, Lacan expone a la rememoración como constituyente de la historia, consiste en el "agrupamiento y sucesión de acontecimientos simbólicamente definidos, puro símbolo que engendra a su vez una sucesión" (1983: 278). Es decir, el pasado se actualiza y construye constantemente en el presente por la estructura de repetición de los acontecimientos por la cual reestructuramos el pasado. ${ }^{16} \mathrm{Como}$ señala Zizek (2003) en la estructura de la repetición hay dos momentos, uno no simbólico y el acto de simbolización. El acontecimiento surge primero como trauma y es en la repetición que se reconoce su necesidad simbólica, para realizarse en el Orden Simbólico. Esto último no podría pasar si no fuera por el primer trauma -o la primera muerte-, a su vez que el hecho de que se repita es también causado por la deuda simbólica. Aquí es donde entra la redención benjaminiana como reconocimiento de esa primera muerte traumática y la necesariedad de su inserción en la memoria actual.

De esta manera, tanto para Lacan como para Benjamin cada nueva integración de un acontecimiento, cada evocación de lo ausente por la palabra, es una modificación de la historia vía rememoración, memoria simbólica. ${ }^{17}$ Como expone Zizek respecto de los acontecimientos del pasado: "su significado, su dimensión histórica se decide después, mediante la inscripción de aquéllos en la red simbólica" (2003: 182). Además, la integración de acontecimientos en el recuerdo, en la memoria, consiste justamente en el concepto benjaminiano de experiencia, modulado como hecho de la tradición, como lo señala en su texto Sobre algunos temas en Baudelaire [1939] (1986). ${ }^{18}$ Así la experiencia es esta rememoración de aquello que pasó inadvertido, que cobra vida en el presente de la memoria, que pervive y retorna porque ha dejado huellas (Collingwood-Selby, 1997). La redención para Benjamin, como expone Abadi "no se apoya en lo que no está en el mundo, sino más bien en lo que está latente en el mundo. Por eso su fundamento se encuentra en una exigencia que habita efectivamente el mundo existente, caído. El pasado está pendiente, y en tanto pendiente, no 'es' al modo del presente, sino como latencia” (2014: 216), y por tanto precisa ser actualizado.

La noción de segunda muerte lacaniana permitiría, así, pensar una constelación tal como la venimos hilando entre las nociones de experiencia y lenguaje, pervivencia y redención en Benjamin. El estatuto del pasado como aquellos deseos truncos que laten en el presente a la manera de una pervivencia, precisan, nos indica Benjamin, la redención. $\mathrm{Si}$, en tanto que fragmentarios son débiles y pueden perderse, la amenaza de una muerte absoluta en el nivel de los significantes apura la exigencia de salvación, en tanto que más allá de la muerte simbólica, Ektòsátas, no hay salvación posible y sólo queda lo infernal. Así, la chispa del pasado que mantiene la esperanza 
ilumina esa salvación a la manera de rememoración. Como posible cruce, la noción de segunda muerte lacaniana nos alumbraría lo que, al final, se encontraría del otro lado de la redención: la esfera del lenguaje, ${ }^{19}$ del reconocimiento y la nominación en la obra tardía de Benjamin. Ahora bien, esto podríamos pensarlo como plantea Zizek (2003), para quien es justamente porque este pasado está pendiente, porque ha tenido su muerte natural, pero no su muerte simbólica, que retorna. La muerte real sin su ajuste de cuentas hace que el mismo regrese, como el espíritu del padre de Hamlet. Ahora bien, en el pensamiento benjaminiano, esto significaría que la redención es análoga a la segunda muerte y no su resistencia, pregunta que dejamos abierta a la luz del final de la tesis III “(...) sólo para esa humanidad redimida se ha hecho convocable su pasado en todos y cada uno de sus momentos. Es que cada uno de sus instantes vividos se convierte en una citation a l'ordre du jour: día que es el del Juicio Final justamente." (Benjamin, 2008: I, II 306).
19. "Lacan's objet a can explain Benjamin's more esoterically and theologically framed conceptions of language. Human language, for Benjamin, can only go so far as to "communicate itself" in language (which is itself a breach and "dislocation") and to an original abyss, the traces of the original word, as Weber puts it, and not to God, as Pizer has it (unless "God" is identified with the leap between human and divine language). The name, as language-matter in Benjamin's hands acquires the status of the Lacanian objet $a$, the imaginary partobject which stands for the unattainable object of desire. For psychoanalysis and for Benjamin, subjectivity is structured by edges and cuts that are linguistic in origin. "God," in modernity, translates into loss and an anxiety that perpetuates itself through the sense of an increasingly less accessible original language for Benjamin. Such an understanding of subjectivity is also psychoanalytic". (Stewart, 2010: 33) 


\section{Dibliografía}

"Abadi, F. (2014). Conocimiento y redención en la filosofía de Walter Benjamin. Buenos Aires: Miño y Dávila.

"Amengual, G. (2008). "Pérdida de la experiencia y ruptura de la tradición. La experiencia en el pensamiento de Walter Benjamin". En Gabriel Amengual; Mateu Cabot y Juan Vermal (Eds.), Ruptura de la tradición. Estudios sobre Walter Benjamin y Martin Heidegger, pp. 29-59. Madrid: Trotta,

» Benjamin, W. (1986b). Sobre algunos temas en Baudelaire. En Sobre el programa de la filosofía futura y otros ensayos [título original Illuminationen- Ausgewählte Schriften]. Barcelona: Planeta- De Agostini

" Benjamin, W. (1986a). El narrador. En Sobre el programa de la filosofía futura y otros ensayos [título original Illuminationen-Ausgewählte Schriften]. Barcelona: Planeta- De Agostini

»Benjamin, W. (1986c). Sobre el lenguaje en general y el lenguaje de los hombres. En Sobre el programa de la filosofía futura y otros ensayos [título original Illuminationen-Ausgewählte Schriften]. Barcelona: Planeta- De Agostini

"Benjamin, W. (1989). Discursos interrumpidos 1. Buenos Aires: Taurus Ediciones

»Benjamin, W. (2008). Obras I, 2. Madrid: Abada

》 Benjamin, W. (2016). Libro de los pasajes. Madrid: Akal

" Bradbury, R. (1998). Crónicas marcianas. Buenos Aires: Minotauro

»Collinwood-Selby, E. (1997). Walter Benjamin: La lengua del exilio. Arcis Escuela de Filosofía. Versión digital

" Comay, R. (2003). Entre la melancolía y el fetichismo: las pérdidas de Walter Benjamin Cuaderno Gris. Época III (7), pp. 97-115. Recuperado de https:// repositorio.uam.es/bitstream/handle/10486/2652/21900_Entre\%20la\%20 melancol\%c3\%ada\%20y\%20el\%20fetichismo.pdf?sequence=1\&isAllowed=y

»Di Pego, A. (agosto, 2015a). La experiencia en Walter Benjamin. Entre el "orden profano" y la "intensidad mesiánica". En X Jornadas de Investigación en Filosofía, Departamento de Filosofía (FaHCE - UNLP), La Plata, Bs As, Argentina. Recuperado de http://jornadasfilo.fahce.unlp.edu.ar/actas-2015/a22.pdf/view

"Giner Ponce, X. (2002). Sobre "la segunda muerte". En NODVS. L'aperiodic virtual de la Secció Clínica de Barcelona, 3. Recuperado de http://www.scb-icf.net/nodus/ contingut/arxiupdf.php?idarticle $=49 \&$ rev $=17$

" Lacan, J. (1976-1980). Kant con Sade (1962) en Escritos, vol. 2. pp. 337-362. Madrid: Siglo XXI

"Lacan, J. (1981). El Seminario de Jacques Lacan. Libro I: Los escritos técnicos de Freud, 1953-54. Buenos Aires: Paidós

" Lacan, J. (1983) El Seminario de Jacques Lacan. Libro Il: El yo en la teoría de Freud y en la técnica psicoanalítica, 1954-1955. Buenos Aires: Paidós

"Lacan, J. (1988). El Seminario de Jacques Lacan. Libro VII: La ética del Psicoanálisis, 1959-1960. Buenos Aires: Paidós. Versión digital http://www.bibliopsi.org/docs/ lacan/09\%20Seminario\%207.pdf 
" Lacan, J. (2003). El Seminario de Jacques Lacan. Libro VIII: La transferencia, 19601961 Buenos Aires: Paidós

" Lacan, J. (1961-1962). Seminario IX: La Identificación, 1961-1962. Inédito, versión digital http://www.bibliopsi.org/docs/lacan/11\%20Seminario\%209.pdf

"Negro, A. M. (2009) Lenguaje, palabra, discurso, en la enseñanza de Jacques Lacan. Revista Affectio Societatis 6 (11). Recuperado de https://revistas.udea.edu. co/index.php/affectiosocietatis/article/view/5260

» Oliveira, C. (2016). Lingua pura e alíngua: um encontró (im)possivel entre Benjamin y Lacan. Revista trágica: estudos de filosofía da imanencia 9 (2) pp.41-50

» Oyarzún, P. (2009). Introducción. En Benjamin, W. La dialéctica en suspenso. Santiago de Chile: Lom.

"Reyes Mate, R. (2006). Medianoche en la historia. Comentarios a las tesis de Walter Benjamin "Sobre el concepto de historia". Madrid: Editorial Trotta

"Stewart, E. (2010). Catastrophe and survival. Walter Benjamin and pshychoanalysis. New York: The Continuum International Publishing Group Inc

"Sargiotto, V. (2014). La narración de la experiencia como forma de tratar con el pasado. Aportes de Hannah Arendt y Walter Benjamin. Revista Horizontes Sociológicos, 3 (5), 106-115. Recuperado de http://aass.org.elserver.com/ojs/index.php/ hs/article/viewFile/34/31

"Tacceta, N. (2012). Supervivencia e imagen: Agamben-Warbug-Benjamin y la historia. Revista Lindes. Estudios sociales del arte y la cultura (5)

"Vargas, S. M. (2014). La vida después de la vida. El concepto de "Nachleben" en Benjamin y Warbug. Thémata Revista de Filosofía, 49, pp. 317-331. doi: 10.12795/ themata.2014.i49.17

»Vargas, S. M. (2017). Nachleben [pervivencia] e historicidad en Walter Benjamin. VERITAS, 38, pp. 35-50. Recuperado de https://scielo.conicyt.cl/pdf/veritas/ n38/0718-9273-veritas-38-00035.pdf

»Zizek, S. (2003). El sublime objeto de la ideología. Buenos Aires: Siglo XXI Editores

"Zelis, O. (2016). El orden simbólico y la concepción de símbolo en Lacan y Peirce. En VIII Congreso Internacional de Investigación y Práctica Profesional en Psicología XXIII Jornadas de Investigación XII Encuentro de Investigadores en Psicología del MERCOSUR. Facultad de Psicología - Universidad de Buenos Aires, Buenos Aires. Recuperado de https://www.aacademica.org/000-044/877.pdf 
